\title{
Informatics: the core and the presentation
}

\author{
Helen Geissinger
}

Instructional Media \& Design P/L, PO Box 112, Brunswick Heads

Australia 2483,e-mail:100235.3713@CompuServe.com

\section{Peter Ho}

School of Computer Science and Engineering

University of New South Wales, Sydney, Australia 2052

e-mail:Peter.Ho@cse.unsw.edu.au

\section{Ken Robinson}

School of Computer Science and Engineering, University of New South Wales, Sydney, Australia 2052, e-mail:

kenr@cse.unsw.edu.au

\begin{abstract}
This paper puts forward a core curriculum and suggests ways to present it in support of the authors' basic premise: that informatics should be part of every curriculum. So many daily routines in the world have become dependent on computer functions that people have a responsibility to understand how they work and take an informed interest in what they do. They also must be able to visualize computer work for the future so that they can help prepare their professions and occupations such that people will still have meaningful work in coming generations.
\end{abstract}

\section{Keywords}

Informatics, context of informatics, curriculum (core), role of CIT 


\section{INTRODUCTION}

Informatics has to do with the ways in which computers operate and with the data these provide, as well as with the transformation of that data into information by interpreters, whether human or other computer applications. People need to understand this connectionbetween computers and humans because the presence of computerized functions is becoming so pervasive in the world in both developed and less-developed countries, even though people living in remote villages may not perceive it. Humankind has the potential to manage its collective life better, if this connection is understood and used beneficially. There are many issues involved, such as impacts on social life and the need for people to develop critical faculties in relation to technical information, as well as ethics and privacy concerns, the social use of computer tools and the quality of decision-making based on computerprovided information. These issues will not go away. People want computers to further their aims, whether professional, in the business or the public sector, but they do not want their thinking and decision-making to be subordinated by computerized procedures.

\section{INFORMATICS IN THE CURRICULUM}

A quick survey of employment advertisements for lecturers in informatics for tertiary institutions shows that the topics such people must be able to teach are technical in nature, such as systems analysis and computer networking. They do not appear to require the teaching of a wider sense of the discipline, e.g. the quality and effectiveness of networked communications or the necessity for the inclusion of a wide spectrum of users when a system is to be designed.

There are of course exceptions to this general situation. For example, one alternative is provided by an Australian university for computing science students. The students in that program are required to complete satisfactorily 21 computing and project units and 5 non-computing units. (Nunn et al., 1995). One of the noncomputing electives is a first-year subject titled 'Technical Communication' in which the curriculum is based on cognitive learning theories and helps students engage in meta-cognition through facilitated experiential learning. The faculty has deliberately chosen to align the competencies for employment identified by a governmental committee with the principles of lifelong learning outlined in another government report. These are used in the curriculum development so that students are made aware of the parameters provided by these two studies and are asked to engage in learning activities which will help them realize the extent and meaning of those ideas. The meta-cognitive activities make it likely that learners will think more deeply about the subject material they will study in other parts of the program. Unfortunately it is an elective rather than a core subject and possibly may attract fewer students once its novelty has worn off. On the other hand one of its 
outcomes may be a desire expressed by successful students that it become a core subject.

Informatics touches on many concerns which are fast becoming a larger part of today's professions. Such an issue is making computer functions more sensitive to human needs and more responsive to the various users of a system. Grémy and Bonnin (1995) documented the development of an automated health information system (AHIS) in a large hospital in France and found that a climate of what they term 'social debate' has arisen around the functions of this system. The earlier introduction of AHISs in hospitals is described as 'brutal', because the systems were designed to meet the needs of certain user groups (such as doctors) and did not meet the needs of other groups such as hospital administration or allied health departments. Grémy and Bonnin note that: '...things happen as if citizens had lost their blind faith [in] the link between happiness and technical progress. They now claim the right to intervene...into the evaluation process of the technical objects.' (page 28). The authors have seen almost violent confrontations among groups which use the AHIS and either find the system works well or does not, according to their experiences. They suggest that the design of any AHIS must centre on the needs of all the groups which will use it, rather than on those advanced by prominent stakeholders.

\section{THE CORE}

Whether or not there are common elements which must be taught to all groups of learners is debatable, especially as the uses are so varied. One could possibly distinguish between the needs of learners in developed countries, where computer use is widespread, and those of learners in less-developed countries where often computerized elements are invisible to those impacted by them. However, students in those countries who will become the future decision-makers, need to understand computers and see how these can accomplish useful things for their nations; they also need to realize how decisions made elsewhere, but impacting locally, may be based on computer analyses. The distinction between learners' needs in developed nations compared with those of less-developed states therefore probably has to do with quantity and not quality. This means that there is an informatics core which is universal while the supporting components vary according to the needs of the particular learner group.

The authors of this paper suggest that the core of informatics topics must include the following:

- technical aspects: hardware and software functions and capabilities;

- current computers applications (contextual examples);

- likely computer applications of the future;

- social impacts and issues. 


\section{Technical aspects}

Learners in every discipline should know exactly what a computer comprises. They should use the terminology correctly and know how each part works. They also need to know the elements of programming and should learn how to program simple functions. From there, they should be helped to extrapolate to sophisticated systems and to be able to describe in general terms how these perform. This knowledge is essential as a basis from which to assess and analyse the functions and impacts of computers in every walk of life. People everywhere should not be talking about 'black boxes' when they discuss the issues.

\section{Current uses of computers}

Obviously this aspect of basic computer knowledge changes rapidly from year to year and will vary from one country to another. Learners need to see computers at work in their own area or, more generally, in their own country so that they can comprehend what and how computers contribute. This will give an understanding of the all-pervasiveness of computers and their contribution to decisions which are made about the governance and economy of every country. Learners also need to see the scope and complexity of computer applications in professional settings.

\section{Future computer applications}

Learners need to know enough about computer applications that they can envision likely possibilities for the future and can make decisions about their own future or help suggest directions which their profession or occupation might take. Heppell (1994) has worked with children in the United Kingdom in a learning centre where they play computer games and investigate educational multimedia. He suggests that the current child in a developed country has great powers of concentration, evidenced by the ability to 'channel hop' rapidly and keep track of a number of television programs simultaneously. He also notes that children are autonomous viewers who want control of their learning experiences (e.g. control of navigation through a multimedia program) and who have '...broader forms of literacy and new media grammars which they bring as real assets into their learning environment.' (page 201). These confident children are computer users now. Adults need to envision future uses which can enable those children to have a productive adulthood.

\section{Social impacts and issues}

Grémy and Bonnin (1995) also looked at the impact which a poorly-designed information system had upon the functioning of a large hospital, and outlined the problems caused by the designers' ignorance of users' needs. They suggest that the designers of any information system should develop a social sense of what goes on in the organization for which the system is intended in order to prevent it causing chaos in the workplace.

One of the biggest impacts on the employment situation in many countries has been the effect of marketplace decisions made by international corporations. 
Suddenly large numbers of people have been dismissed from their places of employment because their jobs have disappeared. Computerized applications have taken over some aspects of their work. There is a huge social problem around the fact of so many unemployed people in so many countries. As Armstrong and Armstrong (1990) note: 'What has been called work...is that which is done for pay or profit in the market...Unpaid work done in the market has frequently been excluded, as has all unpaid and some paid work done in the home or on the streets.' (page 13). People who become long-term unemployed lose recognition as contributors to society's concept of their national economy.

Ohmae (1995) discusses a 'civil minimum' which he calls a 'very moody tiger' which national governments climb on when they succumb to many strong interest groups among their citizens. They are unable to satisfy every group sufficiently to stifle the demands and so must devise a minimum level of service, whether it is in telecommunications or health care, such that people recognize that it is the level that the country as a whole can have. Ohmae suggests that, as the costs of providing services continue to rise, governments and their citizens must think creatively about ways to pay for them. If the time-honoured method of raising taxes is used, it will simply drive away the businesses which currently support the economy, or those businesses will invest more capital in machines and automation.

Issues such as these (unemployment and the civil minimum) should not be confined to philosophy or political studies. They belong in the core informatics curriculum where the learners who intend to design and use computers, can examine the many social aspects which will be impacted.

In addition, informatics should be taught across the curriculum to help learners develop their critical faculties with regard to information delivered by the computer. There is a tremendous range of offerings already, from educational multimedia programs developed for specific target groups (e.g. A.D.A.M. for learners of human anatomy and physiology) to CD-ROM 'books' like the Encyclopedia Britannica through to 'edutainment' and 'infotainment', offerings which attract varied groups of viewers. Learners need to develop abilities to critique them, so that the educational content, if any, can be distinguished from the media 'push' (Kelly and Wolf, 1997). One way to develop these abilities is for learners to engage in the production of multimedia themselves; they can critique other presentations since they understand the technologies used and biases involved in choosing one element over another.

\section{THE PRESENTATION}

\section{Visual memories}

Good visual presentations seem to provide strong memory traces. Children tend to remember what they have seen on television better than material they have read, even when the topic is the same. Spinney (1997) reports that children who have grown up with television, have recognition skills associated with the visual 
medium which are better developed than those they have acquired for reading with understanding. While it may be true that 'a picture is worth a thousand words', and that many people remember something they have seen better than something they have read, it is also true that pictures can be constructed of clever visual effects. Visual presentations, e.g. television and film, are ephemeral, yet their impact may be so strong that learners may wish to take what they see is 'true'. Thus, even children need a knowledge of informatics to inform their visual perceptions.

\section{Discussion of perceptions}

Conversation Theory (Pask and Boyd, 1987) shows how the computer can help people understand each other by analysing the words they use in discussing a concept and showing the areas in which their discussion is congruent. For example, negotiators trying to find common ground among opposing parties and in education learners who want to discover what it means to 'be' a member of a discipline, such as being an engineer or a medical doctor. Grémy and Bonnin (1995) suggest that conversation must occur around any mooted technical innovation so that it can fit with the needs of those who will use it. Because, for example, an automated health information system (AIS) may aid, simulate or duplicate human intellectual activities, the authors suggest that: '....all such AIS should be evaluated with special reference to the concepts and methods of sociology, psychosociology, and organizational sciences.' These authors think that an active ongoing conversation about the innovation among the users is very important.

\section{Microworlds}

Eklund (1995) gives an example of teaching electronically using 'micro-worlds'. He described commercial software which helped students investigate particular phenomena. Others have used custom software to develop the microworld concept. The techniques allow learners of any age or background to enter 'worlds' in which they can explore and experiment without serious consequences. If they are active in that field of knowledge, they can also input findings from their own work and manipulate them within the 'world'. Authors of microworld software report great user enthusiasm for the 'game' aspect of the software while also providing evidence of deep learning.

\section{Across the curriculum}

As mentioned above, valuable learning experiences can be provided by perceptions gained from visual media in an explorative guided discussion of ideas engendered both by personal social knowledge and knowledge discovered in microworlds. Heppell's (1994) reference to children having '...broader forms of literacy...' shows that, more than ever before, teaching must accommodate many different approaches to knowledge. Teaching informatics across the curriculum is fast reaching a high degree of necessity. The teaching methods, as well as supporting theories, must allow a wide range of approaches and accept as valid a variety of outcomes. 


\section{Making meaning}

There is a debate in the teaching field around the merits of instructivism and constructivisim. Instructivism requires a statement of goals and objectives set by the developer of the content. Good instructivist teaching is evidenced when the learner demonstrates certain behaviour as a result of that interaction (Rieber, 1992). Constructivism requires learners to make sense from their experiences, mental structures and beliefs and to use these constructions to interpret happenings and objects in the world. Khoo and Lou (1996) state that: a '..constructivistic environment..naturally promotes self-directed learning', but then offer a caveat that high achievers tend to do better in a constructvist environment compared with low achievers. Mezirow thinks that it is a characteristic of adult learning that allows a learner to construct a meaning which is: '..more inclusive, discriminating, integrative and permeable (open)..' He does not suggest that a learner needs to be a high achiever, but posits that it is a function of adult development. Khoo and Lou (1996) studied primary school teachers as novice multi-media developers and found that some of their learners were afraid of the technologies they were invited to use and constrained themselves from being exploratory and innovative. Norman's Schemata theory says that the way in which a learner interprets new knowledge is unique and is based on schemata already in place from prior learning. If the framework is skimpy and perhaps even misconceived, the learner will interpret new knowledge very differently than would someone who has a better basic framework at the beginning.

There appears to be room here for all three views of learning. Instructivist teaching can help learners build a useful framework through which to develop deeper understandings as they explore and 'construct' a subject area more fully. Mature reasoning and reflection will help learners place ensuing discoveries in context.

\section{The gap}

As Khoo and Lou (1996) have shown with primary school teachers, there is a huge gap in the knowledge and skills regarding informatics in those who must help the current body of learners build their frameworks. While there are arguments for face-to-face teaching, it is probably appropriate that an informatics subject (or the informatics part of another subject) should be taught electronically. The teaching can reach a global audience, if necessary, and can help bring an enormous number of would-be practitioners into the knowledge area quickly. On-line subjects are being taught successfully and the tools for on-line work by individuals and groups of students are readily available and easy to use. O'Neill (1997), in looking at some of the offerings on the Internet, suggests that the best uses of the Internet are made by educators and researchers. Writing for Australian newspaper readers, she finds that a poll of 'netizens' showed that, although $21 \%$ use the Internet primarily for entertainment, $15 \%$ use it for e-mail and $12 \%$ for general research (O'Neill, 1997). She notes that all learners can be helped through discussion in a medium such as e- 
mail to acquire the skills needed to critique information at the thinking level they have reached and can then research the Internet capably.

\section{Addressing the gap}

Collis provides examples of good ways to use the Internet for teaching through her publications which include a URL:

http://www.to.twente.nl/ism/online96/week/week1/followu.htm

for the outline of an on-line subject she taught in 1996. She models good on-line teaching: She lists things to do and gives the reasons for doing them. She provides workspace for all her learners to access, see others' contributions and input their own, and she sets up information/discussion/ feedback areas so that the learners are updated, can engage in discussion, and receive feedback on their input. E-mail pages and biographical materials for each learner are readily available, so that participants can see something about each other and can chat. She ensures that the materials the learners should work with are available at certain Web sites or she gives advice on ways to do their own searches and the steps they should take once they find what appears to be appropriate material. She keeps everyone on target, on-line and participating in the work by using a variety of tools and methods; she values each contributor's participation. Whether or not she so intends, Collis utilises the ROPES+ framework espoused by Hannafin and Rieber (1989) which emphasizes: '..relationships among external capabilities of technologies, task, and performance requirements, known causal relationships in learning, and the processing capabilities of individual learners.'. This framework may be the best for the design of courses which will bring adults (especially professionals) into that state of cognitive awareness in which they understand computers, the capabilities and can predict likely future applications. Then those who are teachers will be equipped well to teach their confident, button-pressing students.

\section{REFERENCES}

Armstrong, P. and Armstrong, H. (1990) Theorizing women's work. Garamond Press, Toronto, 13.

Eklund, J. (1995) A project approach to teaching and learning with technology: A case study with Microworlds Project Builder, in Learning with technology, ASCILITE conference proceedings (eds. J. Pearce and A. Ellis), The Science Multimedia Teaching Unit, University of Melbourne, Melbourne, Australia, 126-130.

Grémy, F. and Bonnin, M. (1995) Evaluation of automatic health information systems: What and how?, in Assessment and Evaluation of Information Technologies (eds. E.M.S.J van Gennip and J.L. Talman), IOS Press, Oxford, 9-34. 
Hannafin, M.J. and Rieber, L.P. (1989) Psychological foundations of instructional design for emerging computer-based instructional technologies: Part II. Educational Technology Research and Development, 37 (2), 102-114.

Heppell, S. (1994) Learning and the children of the information age, in Proceedings of the Second Multimedia Symposium, Perth, Australia, 200-203.

Kelly, K. and Wolf, G. (1997) We interrupt this magazine for a special bulletin -PUSH! Wired, 5 (2), 12-23.

Khoo, C.C. and Lou, C.T. (1996) From virtual novices to real interactive multimedia producers: a research study, in From virtual to reality, Apple University Conference, The University of Queensland. See also: http://www.uow.edu.au/auc/Conf96/Papers/KhooCC.html.

Mezirow, J. (1978). Perspective transformation. Adult Education, 28 (2), 100-110.

Nunn, J., Else, D., Pitt, J. and Carroll, P. (1995) Computing, communicating and contracting: A first-year experience in lifelong learning, in Learning with technology, ASCILITE conference proceedings (eds. J. Pearce and A.Ellis), The Science Multimedia Teaching Unit, University of Melbourne, Melbourne, Australia, 432-440.

Ohmae, K. (1995) The end of the nation state. The rise of regional economies. The Free Press, New York, 46-57.

O'Neill, H. (1997) The Internet backlash. The Weekend Australian, 15-16 March 1997, 1 (Syte section).

Pask, G. and Boyd, G. (1987) Conversation Theory as basis for instructional design, in Interactive media: Working methods and practical applications (ed. D. Laurillard), Holstead Press (Div. John Wiley \& Sons Ltd.), New York, 9196.

Rieber, L.P. (1992) Computer-based micro-worlds: A bridge between constructivism and direct instruction. Educational Technology, Research and Development, 40 (1), 93-105.

Spinney, L. (1997) Square eyes and strong memories. New Scientist, 153 (2073), 5.

\section{BIOGRAPHY}

Helen Geissinger is an educational developer interested in the effects of the use of various media in adult learning. She has worked with a number of universities in the development of study programs which have used multiple media and has then researched the learning outcomes of the student groups. She is currently researching the effects of innovative teaching in Australian tertiary institutions which use computer media.

Peter Ho has a degree in computer science (Honours) from The University of New South Wales (UNSW), Australia. He has nine years industry experience as a software engineer and as a consultant. He joined the School of Computer Science and Engineering at UNSW in 1991, where he initiated and worked on a number of 
projects related to distance learning, multimedia tools for use in education, home computing and software engineering.

Ken Robinson is a senior lecturer and head of the Department of Software Engineering in the School of Computer Science and Engineering at the University of New South Wales (UNSW). He has a long record of teaching computer science and software engineering with a special interest in rigorous software development methods, and in the recognition of computing as an engineering discipline. He played a leading role in the introduction of a new computer engineering course in 1989 and a new software engineering course in 1997 at UNSW. 